\title{
BLOOD LOSS IN THE MINIMALLY INVASIVE POSTERIOR APPROACH TO TOTAL HIP ARTHROPLASTY: A COMPARATIVE STUDY
}

\author{
Jose Ricardo Negreiros Vicente, Alberto Tesconi Croci, Olavo Pires de Camargo
}

doi: $10.1590 / \mathrm{S} 1807-59322008000300011$

Vicente JRN, Croci AT, Camargo OP. Blood loss in the minimally invasive posterior approach to total hip arthroplasty: a comparative study. Clinics. 2008;63:351-6.

AIMS: Our primary aim was to evaluate whether there is really less bleeding in patients for whom the minimally invasive posterior approach is used in comparison with the direct lateral approach for primary total hip arthroplasty. Our secondary aim was to evaluate the clinical functional results after six months as well as the postoperative radiographic result.

METHODS: In a comparative non-random prospective study, 76 adult patients underwent elective total hip arthroplasty using one of two approaches. The minimally invasive posterior approach (34 cases; mini-incision group) was compared with the standard direct lateral approach (42 cases; control group).

RESULTS: Lower total estimated bleeding (means of $1083.5 \mathrm{ml}$ versus $1682.3 \mathrm{ml}$; $\mathrm{p}<0.001$ ) and lower intraoperative bleeding (means of $745.6 \mathrm{ml}$ versus $1282.8 \mathrm{ml}$; p < 0.001) were found in the mini-incision group. There was, however, no difference in the volume of blood drained after the operation (means of $340 \mathrm{ml}$ and $399 \mathrm{ml} ; \mathrm{p}=0.77$ ). There was also a difference between the two groups regarding the need for allogenic transfusion $(8.8 \%$ in the mini-incision group versus $28.6 \%, \mathrm{p}=0.02)$. We observed a better clinical result in the mini-incision group $(\mathrm{p}=0.002)$ despite the lack of difference between the two groups in relation to the radiographic result.

DISCUSSION: Our results draw attention to the possibility that other authors may have underestimated blood losses when using minimally invasive approaches.

CONCLUSION: The minimally invasive approach gave rise to a positive final impression with regard to lower blood loss.

KEYWORDS: Hip. Arthroplasty. Minimally. Invasive. Blood.

\section{INTRODUCTION}

The traditional approaches most commonly utilized for primary total hip arthroplasty are the posterior approach and the direct lateral approach. ${ }^{1,2}$ There is a supposed risk of weakening of the abductor mechanism in the lateral approach and a supposed increase in instability in the posterior approach, ${ }^{3}$ while infection is always a concern. ${ }^{4}$ With the advent of minimally invasive approaches, some authors have reported supposed advantages in the latter approaches, such as less bleeding, shorter surgery duration, and a lower transfusion rate..$^{5,6}$

Department of Orthopedics, Faculdade de Medicina da Universidade de São Paulo - São Paulo/SP, Brazil. rrnegreiros@gmail.com

Received for publication on February 07, 2008

Accepted for publication on March 24, 2008
There is, however, some controversy in the literature concerning estimated blood loss in relation to the real calculated loss, with quantities that are significantly higher than in more recent studies on minimally invasive approaches..$^{7,8}$ The methodology used for measuring intraoperative blood loss is highly variable, ranging from the use of mathematical formulae to blood parameter measurements.

The primary aim of the present study was to evaluate whether there is really less bleeding in patients for whom the minimally invasive posterior approach is used in comparison to the direct lateral approach. Our secondary aim was to evaluate the clinical results after six months as well as the postoperative radiographic results, with special attention paid to restoration of the rotation center of the prostheses and alignment of the acetabular and femoral components. 


\section{MATERIALS AND METHODS}

Approval for this study was granted by the Ethics Committee of the University of São Paulo Medical School. The sample size was calculated from an initial sample of 20 cases, which showed that the standard deviation for blood loss was 512 . We considered $400 \mathrm{ml}$ of bleeding to be clinically significant (i.e., the volume corresponding to one unit of red blood cell concentrate). A study power of $90 \%$ was adopted, and the minimum number of patients for each group was 34 .

As a result, 76 cases of total hip arthroplasty due to a diagnosis of primary or secondary osteoarthrosis were studied (Tables 1 and 2). These were divided into two groups of patients to compare the minimally invasive posterior $\operatorname{approach}^{6}$ (34 cases; mini-incision group) and the standard direct lateral approach (42 cases; control group). ${ }^{2} \mathrm{We}$ considered minimally invasive access to consist of incisions of up to $11 \mathrm{~cm}$ in length, with minimal dissection of deep tissues. The minimally invasive technique that we used was a modification of the posterior access described initially by Moore ${ }^{1}$. We performed muscle-sparing tenotomy on the external rotators of the femur while preserving the tendon of the piriformis muscle and part of the tendon of the quadratus femoris muscle. In addition, we preserved the posterior and anterior portions of the joint capsule by resecting only its lateral portion ${ }^{6}$ (Figure 1).

Table 1 - Patient Demographics

\begin{tabular}{llll}
\hline Parameter & Mini-incision group & Control group & P value \\
\hline Number of patients & 34 & 42 & - \\
Age & $\begin{array}{l}50 \pm 13 \\
\text { (range 27-79years) }\end{array}$ & $\begin{array}{l}57 \pm 11 \\
\text { (range35-75years) }\end{array}$ & $0.02^{*}$ \\
Body mass index & $\begin{array}{l}27 \pm 4 \\
\left.\text { (range 20-36kg/m }{ }^{2}\right)\end{array}$ & $\begin{array}{l}27 \pm 4 \\
(\text { range20-37kg/m²) }\end{array}$ & 0.40 \\
Hb value (g/dl) preop & $13.8 \pm 1.2$ & $13.9 \pm 1.1$ & 0.57 \\
Ht value (\%) preop & $40.7 \pm 3.5$ & $41.6 \pm 3.5$ & 0.25 \\
Male/female & $21 / 13$ & $26 / 16$ & 1.0 \\
Right hip/left hip & $19 / 15$ & $21 / 21$ & 0.65 \\
\hline
\end{tabular}

Table 2 - Initial diagnosis

\begin{tabular}{lccc}
\hline Diagnosis & $\begin{array}{c}\text { Mini-incision } \\
\text { group }\end{array}$ & $\begin{array}{c}\text { Control } \\
\text { group }\end{array}$ & P value \\
\hline Rheumatic disease & $26.5 \%$ & $16.7 \%$ & - \\
Primary osteoarthritis & $35.3 \%$ & $31 \%$ & - \\
Secondary osteoarthritis & $38.2 \%$ & $52.3 \%$ & - \\
& & & $\mathrm{p}=0.63$ \\
\hline
\end{tabular}

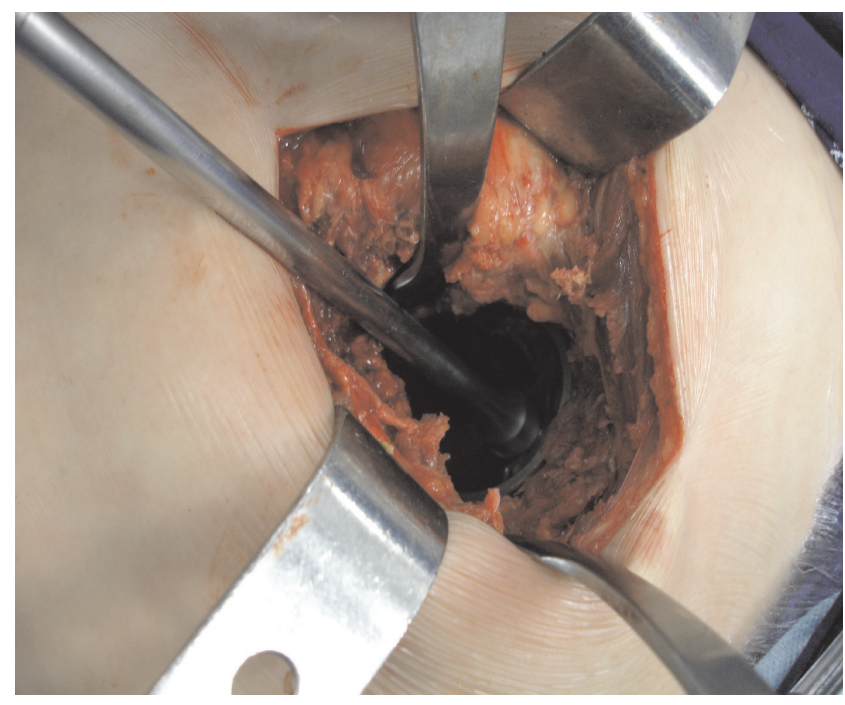

Figure 1 - Inserting acetabular component

All patients were selected from a waiting list for total hip arthroplasty at the Hip Group of the Orthopaedics and Traumatology Institute of the University of São Paulo. The operations were performed between July 2004 and July 2006, and, in all cases, uncemented prostheses were used. The mean age of the mini-incision group (50.1 years) was lower than the mean for the control group (56.8 years) $(\mathrm{p}=$ 0.017).

This was a comparative non-random prospective study in which the null hypothesis was equality of blood loss between the two groups of patients and the alternative hypothesis was a difference in blood loss between the two groups of patients.

Patients were excluded from the study if they presented the following: any type of coagulopathy such as the use of anticoagulants or platelet antiaggregants; hypertension without medicinal control; any previous hip surgery; and sequelae of hip developmental dysplasia that might have led to an ectopic femoral head. Death and loss to followup within the first six months after surgery were additional exclusion criteria. The first 34 patients on the waiting list were selected for the mini-incision group, and the next 42 patients formed the control group.

All patients were given the same regimen of postoperative analgesia, which consisted of $100 \mathrm{mg}$ of tramadol (Pfizer ${ }^{\circledR}$ ) administered intravenously every eight hours and $100 \mathrm{mg}$ of ketoprofen (Eurofarma $\left.{ }^{\circledR}\right)$ given as a single intravenous dose every day until hospital discharge. Antithrombotic prophylaxis with $40 \mathrm{mg}$ of enoxaparin (Sanofi-Aventis ${ }^{\circledR}$ ) was administered subcutaneously to all patients beginning immediately after the operation and continuing by means of a daily dose until 21 days after surgery.

All patients were discharged after five days in the hospital and given medication for antithrombotic and analgesic 
prophylaxis (paracetamol, $500 \mathrm{mg}$ orally every eight hours, only if necessary). Physiotherapy, consisting of active assisted flexion and extension of the ankles and knees using an abduction pillow, was initiated on the first postoperative day for all patients and continued until discharge.

Training for partial load-bearing walking was initiated on the second postoperative day for all patients. Full loading was implemented only six weeks after surgery. The patients' progress was followed up through day-care, with scheduled appointments upon completion of one, three, six, 12, and 24 weeks after the operation.

Bleeding was measured using three methods ${ }^{8}$. The first measurement, the difference in the weights of 30 large surgical pads before and after the operation, was obtained using a precision balance. An approximation was made between volume and mass such that one gram was taken to be equivalent to one milliliter. The second measurement was the difference between the volume of serum initially infused into the surgical field and the final aspirated volume in the surgical aspirator. Three liters of $0.9 \%$ saline solution were used for washing and irrigation in all patients. The third measurement was the volume collected and discarded from the vacuum drain prior to its withdrawal on the second postoperative day. The sum of these three measurements was considered to be the estimate of the total bleeding from each patient.

All patients in this study underwent spinal anesthesia using $0.5 \%$ isobaric bupivacaine. For volemic replacement, the anesthesia team utilized Ringer lactate serum at a dose of 10 to $15 \mathrm{ml} / \mathrm{kg}$ of weight per hour, along with a $6 \%$ solution of hydroxyethylamide colloid (Voluven ${ }^{\circledR}$ ), at a maximum dose of $1500 \mathrm{ml}$ over the first 24 hours.

The criteria that the anesthesia and clinical teams adopted for blood transfusion were: a hemoglobin level lower than $8 \mathrm{~g} / \mathrm{dl}$, a heart rate greater than 120 together with a mean arterial pressure less than $80 \mathrm{mmHg}$ or a mean systolic arterial pressure less than $100 \mathrm{mmHg}$, and a diastolic pressure less than $60 \mathrm{mmHg}$. Other criteria were: oximetry less than $90 \%$ and the presence of tachypnea (respiratory rate greater than 20). The presence of any of these signs, or the need for vasoactive drugs to maintain arterial pressure, was considered to be a "triggering situation" for blood transfusion.

Furthermore, we recorded the number of units of blood cell concentrates transfused into each patient during his o her hospital stay. We also compared the clinical and radiographic results between the two groups. This was done using the Harris hip score before surgery and six months after surgery and assessing the extent of restoration of the center of rotation of the prosthesis through measurements of the medial, lateral, and vertical offsets (lower values than pre-op defining a good result), acetabular inclination (35-50 degrees defining a good result), and femoral inclination (0-5 degrees of valgus) defining a good result (Table 3). ${ }^{9}$

This was a two-tailed study. Data with a normal distribution were evaluated by parametric tests. Comparisons between the types of procedure performed were made using the Student's T-test on the two groups. Data that did not present a normal distribution were evaluated by nonparametric tests. Comparisons between the two groups were made using the Mann-Whitney test. Qualitative (nonnumerical) data are shown in the two-tailed contingency tables and were analyzed using the chi-square test or Fisher exact test when necessary. The significance level used was $\mathrm{p}=0.05$.

\section{RESULTS}

Lower total estimated bleeding (means of $1083.5 \mathrm{ml}$ versus $1682.3 \mathrm{ml} ; \mathrm{p}<0.001)$ and lower intraoperative bleeding (means of $745.6 \mathrm{ml}$ versus $1282.8 \mathrm{ml}$; p <0.001) were found in the mini-incision group. There was, however,

Table 3 - Surgery duration, incision length, transfusion rate, prosthesis model, clinical and radiographic results

\begin{tabular}{|c|c|c|c|}
\hline Parameter & Mini-group & Control group & $\mathrm{P}$ value \\
\hline Surgery duration & $97.5 \pm 26$ (range, $50-174$ minutes) & $125 \pm 40$ (range, $50-220$ minutes) & $0.001 *$ \\
\hline Incision lenght & $9.7 \pm 1$ (range, $7-11$ centimeters $)$ & $17 \pm 3$ (range, $11-29$ centimeters $)$ & $<0.001 *$ \\
\hline Transfusion rate ( number of patients) & $3 / 34$ & $12 / 42$ & $0.02 *$ \\
\hline Prosthesis model (Aesculap®,Germany) & 29 & 10 & - \\
\hline Prothesis model (Lepine®, France) & 5 & 24 & - \\
\hline Prothesis model (Baumer®, Brazil) & 0 & 8 & - \\
\hline Harris hip score difference after 6 months & $51.8 \pm 16($ range $,-10,+72)$ & $43.3 \pm 13$ (range, $-4,+67)$ & $0.002 *$ \\
\hline Cup positioning (35-50 degress/outliers) & $32 / 2$ & $35 / 7$ & 0.17 \\
\hline Femoral positioning (0-5degress valgus/outliers) & $32 / 2$ & $37 / 5$ & 0.45 \\
\hline Restoration of center of rotation(good/poor) & $31 / 3$ & $36 / 6$ & 0.72 \\
\hline
\end{tabular}


no difference in the volume of blood drained after the operation (means of $340 \mathrm{ml}$ and $399 \mathrm{ml} ; \mathrm{p}=0.77$ ). There was a difference in the need for allogenic transfusion between the two groups $(8.8 \%$ in the mini-incision group versus $28.6 \%$, $\mathrm{p}=0.02)$, and the mean number of units of red blood cells transfused was lower in the mini-incision group $(0.16$ units versus 0.28 units).

We observed a lower mean duration of surgery in the mini-incision group (97.5 min versus $125 \mathrm{~min}, \mathrm{p}=0.001$ ) and a shorter mean incision length $(9.7 \mathrm{~cm}$ versus $17 \mathrm{~cm}$, $\mathrm{p}<0.001$ ) (Table 3).

One patient from the control group was excluded due to progression to acute renal failure in the early postoperative period and death on the $30^{\text {th }}$ day of hospital stay despite intensive care.

The principal author and main surgeon performed the operations on all 34 patients who underwent the minimally invasive posterior approach and on 27 of the 42 patients in the control group. For control group patients, there was no significant difference in total bleeding between the operations performed by the main surgeon and those performed by the other surgeons on the team (means of $1655 \mathrm{ml}$ and $1725 \mathrm{ml}$, respectively; $\mathrm{p}=0.77$ ).

Two patients in the mini-incision group presented complications. There was one case of fracture of the medial acetabular wall (which consolidated after 12 weeks) and one case of acetabular loosening after 12 months. The latter case showed good evolution after acetabular revision.

Five patients in the control group presented complications. Two cases were femoral fractures with intraoperative cerclage and good evolution. One was a case of dislocation with closed reduction, and one was a superficial infection, for which antibiotic therapy was administered for three weeks. The fifth of these patients had apraxia of the contralateral ulnar nerve caused by compression of the contralateral upper limb due to the weight of the body in the lateral decubitus. This patient experienced remission after eight weeks.

\section{DISCUSSION}

Some authors have defined sample groups for the minimally invasive approach that included a preselection bias (as admitted by these authors themselves) and tended towards a significant predominance of the male gender..$^{10,11}$

Regarding our patients' ages, we observed a significant difference between the two groups: the mean age of the mini-incision group (50.1 years) was lower than the mean for the control group (56.8 years) $(\mathrm{p}=0.017)$. We stress that the mean ages of these two groups were lower than the means in most other studies, which demonstrated mean ages of over 60 years.

We noted, however, that the incidence of primary osteoarthritis in the patients assessed in those other studies was higher than in our study. This explains the lower mean age in our sample since patients with rheumatic or systemic diseases tend to have an earlier indication for surgery than patients with primary osteoarthritis, for whom the typical age range is around the seventh decade of life. ${ }^{6,12}$

The lower mean age of the posterior mini-incision group in relation to the lateral group might be considered to be a bias favoring the posterior mini-incision group. Patients with an early indication for total hip arthroplasty, however, tend to be in a more serious clinical condition since this involves a decision to undertake definitive and irreversible surgical treatment.

Most authors have reported lower bleeding when using minimally invasive approaches. From an analysis of only those studies in which a comparison between the minimally invasive posterior approach and the traditional approach was made, we perceived that the bleeding estimates were lower with the less invasive approach. These estimated quantities were significantly lower (ranging from $152 \mathrm{ml}$ to $598 \mathrm{ml}$ ) than in our sample, for which the estimated mean for total bleeding in the mini-incision group was $1083.5 \mathrm{ml}$. $^{6,13}$

Our bleeding estimate for the minimally invasive posterior approach was significantly higher than that published in the literature, but the mean volume of transfused red blood cells ( 0.16 units) and the proportion of transfused patients were both significantly lower (8.8\%) than those described in the literature ( $43 \%$ and $65 \%$ ). For these reasons, we were faced with contradictory results. These can be explained only by speculating that most authors underestimated the true bleeding that took place in their total hip arthroplasty operations..$^{12,14}$

Most studies are unclear about how their estimates of bleeding were obtained. We further highlight that optimism and enthusiasm regarding new techniques may constitute a methodological bias that leads the team or the surgeon to downplay blood losses.

One multicenter study, involving 225 European reference centers that evaluated 2054 patients who underwent primary total hip arthroplasty, showed that there was a great discrepancy between the estimated loss (mean of $750 \mathrm{ml}$ ) and the true calculated loss (mean of $1944 \mathrm{ml}$ ). The latter quantity was closer to our estimate for patients undergoing the direct lateral traditional approach, for which the estimated mean was $1682.3 \mathrm{ml}^{8}$.

Other authors have reported calculated losses of 1428 $\mathrm{ml}$ and a drop in hemoglobin levels of about $4 \mathrm{~g} / \mathrm{dl}$ in patients who underwent total hip arthroplasty ${ }^{7}$. These results substantiate this underestimation. 
When using the minimally invasive posterior approach, some authors have reported very low mean durations for the operation, such as 37 minutes, ${ }^{15} 57$ minutes, ${ }^{14}$ and 70 minutes. ${ }^{16}$ Our mean $(97.5 \mathrm{~min}$ ) was slightly greater than that found by most other authors. This can be explained by the significant variation in our surgical team during the study period (due to rotation among residents), although the main surgeon remained the same.

Regarding cosmetic results, in our experience, we noticed that incisions smaller than $9 \mathrm{~cm}$ (i.e., about 7 to $8 \mathrm{~cm}$ ) tended to present hypertrophic healing, which is esthetically unfavorable in comparison to the traditional approach. This has been previously studied by plastic surgeons. ${ }^{17}$

We noticed a better clinical result in the mini-incision group (difference in mean Harris hip score from before to after the operation of 51.8 versus $43.3, \mathrm{p}=0.002$ ) despite the short-term follow-up of the hip replacement results. Most authors have shown no real benefits to using minimally invasive approaches, with an increased risk of complications observed when using the two-incision minimally invasive approach. ${ }^{18-20}$ In our study, the short-term follow-up represents a major bias with regard to reaching any conclusions about better results in the mini-incision group.

Notwithstanding the good radiographic results, we noticed that some patients' presentation of severe hypertrophic osteoarthritis and larger femoral and acetabular diameters might be a contraindication with regard to minimally invasive access. In such patients, we observed a certain amount of technical difficulty, with inadequate preparation of the host bone and unexpected lateralization of the center of rotation. The acetabular components were also undersized, resulting in an unsatisfactory biomechanical result (Figure 2). Traditional accesses are probably indicated more for such patients, thereby enabling adequate viewing of the anatomical site. We did not have any difficulty when preparing the femoral component using the minimally invasive approach, although an increased risk of varus position has been claimed previously. ${ }^{11}$

With regard to ethical issues, one author has stated that about $19 \%$ of the internet sites for members of the

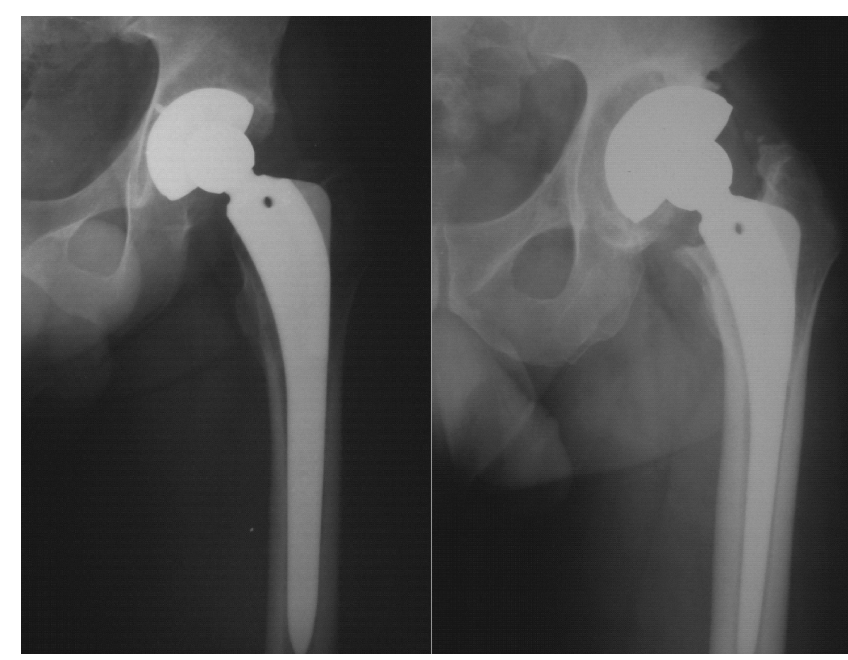

Figure 2 - Good radiographic result (left) and poor result (right), with lateral rotation center

American Society of Hip Surgery, which comprises a select group of surgeons, showed references to minimally invasive approaches. Only one-third of these references warned of the potential risks, while $44 \%$ showed advantages without any scientific basis. Some even tended toward promotional exaggeration. ${ }^{21}$

Attention is drawn to the risks and technical difficulty among obese patients and those with larger anatomical dimensions. Follow-up studies over longer periods may provide clarification regarding possible advantages in relation to the traditional approaches.

\section{CONCLUSION}

The minimally invasive approach gave rise to a positive final impression with regard to lower blood loss, good alignment of the prostheses components, and a slightly better clinical result.

\section{ACKNOWLEDGEMENTS}

To Mrs. Diva Godoi for technical help.

\section{REFERENCES}

1. Moore AT. Metal hip joint: a new self-locking vitallium prosthesis. South Med J. 1952; 45:1015.

2. Hardinge K. The direct lateral approach to the hip. J Bone Joint Surg Br. 1982;64:7-9.

3. Ritter MA, Harty LD, Keating ME, Faris PM, Meding JB. A clinical comparison of the anterolateral and posterolateral approaches to the hip. Clin Orthop. 2001;385:95-9.
4. Cabrita HB, Croci AT,Camargo OP, Lima ALLM. Prospective study of the treatment of infected hip arthroplasties with or without the use of an antibiotic-loaded cement spacer. Clinics. 2007;62:99-108

5. Berger RA, Jacobs JJ, Meneghini RM, Valle CD, Paprosky W, Rosenberg AG. Rapid rehabilitation and recovery with minimally invasive total hip arthroplasty. Clin Orthop. 2004;429:239-47. 
6. Wenz JF, Gurkan I, Jibodh SR. Mini-incision total hip arthroplasty: a comparative assessment of perioperative outcomes. Orthopedics .2002;25:1031-43.

7. Pierson JL, Hannon TJ, Earles DR. A blood-conservation algorithm to reduce blood transfusion after total hip and knee arthroplasty. J Bone Joint Surg Am .2004;86:1512-8.

8. Rosencher N, Kerkkamp HEM, Macheras G, Munuera LM, Menichella G, Barton DM et al. Orthopedic Surgery Transfusion Hemoglobin European Overview (OSTHEO) study: blood management in elective knee and hip arthroplasty in Europe. Transfusion .2003;43:459-69.

9. Russotti GM. Proximal placement of the acetabular component in total hip arthroplasty. A long-term follow-up study. J Bone Joint Surg Am. 1991;73:587-92.

10. Berger RA. Total hip arthroplasty using the minimally invasive twoincision approach. Clin Orthop. 2003;417:232-41.

11. Woolson ST, Mow CS, Syquia JF, Lannin JV, Schurman DJ. Comparison of primary total hip replacements performed with a standard incision or a mini-incision. J Bone Joint Surg Am .2004;86:1353-8.

12. Swanson TV. Early results of 1000 consecutive, posterior, single-incision minimally invasive surgery total hip arthroplasties. J Arthroplasty .2005;20:26-32

13. Wright JM, Crockett HC, Delgado S, Lyman S, Madsen M, Sculco TP. Mini-incision for total hip arthroplasty. A prospective, controlled investigation with 5-year follow-up evaluation. J Arthroplasty. 2004;19:538-45.
14. Goldstein WM, Branson JJ, Berland KA, CST, FA, Gordon AC. Minimalincision total hip arthroplasty. J Bone Joint Surg Am. 2003;85:33-8.

15. Hartzband MA. Posterolateral minimal incision for total hip replacement: technique and early results. Orthop Clin North Am .2004;35:119-29.

16. Chimento GF, Pavone V, Sharrock N, Kahn B, Cahill J, Sculco TP. Minimally invasive total hip arthroplasty. A prospective randomized study. J Arthroplasty .2005;20:139-44.

17. Mow CS, Woolson ST, Ngarmukos S, Park EH, Lorenz PH. Comparison of scars from total hip replacements done with a standard or a miniincision. Clin Orthop . 2005;441:80-5.

18. Ogonda L, Wilson R, Archbold P, Lawlor M, Humphreys P, O’Brien $S$ et al. A minimal-incision technique in total hip arthroplasty does not improve early postoperative outcomes. A prospective, randomized, controlled trial. J Bone Joint Surg Am. 2005;87:701-10.

19. Archibeck MJ, White Jr RE. Learning curve for the two-incision total hip replacement. Clin Orthop .2004;429:232-8.

20. Bal BS, Haltom D, Aleto T, Barret M. Early complications of primary total hip replacement performed with a two-incision minimally invasive technique. J Bone Joint Surg Am. 2005; 87:2432-8.

21. Klein GR, Parvizi J, Sharkey PF, Rothman RH, Hozack WJ. Minimally invasive total hip arthroplasty: internet claims made by members of the hip society. Clin Orthop . 2005;441:68-70. 